\title{
A multi-criteria decision making approach for public lighting system selection
}

\author{
Maria Cristea $^{1, *}$, Radu Adrian Tîrnovan ${ }^{2}$, Ciprian Cristea $^{3}$, Constantin Sorin Pică ${ }^{4}$ and Cristian Făgărăşan ${ }^{5}$ \\ ${ }^{1}$ Technical University of Cluj-Napoca, Faculty of Electrical Engineering, fagarasan maria@yahoo.com, România \\ ${ }^{2}$ Technical University of Cluj-Napoca, Faculty of Electrical Engineering, radu.tirnovan@enm.utcluj.ro, România \\ ${ }^{3}$ Technical University of Cluj-Napoca, Faculty of Electrical Engineering, ciprian.cristea@emd.utcluj.ro, România \\ ${ }^{4}$ Technical University of Cluj-Napoca, Faculty of Electrical Engineering, sorin.pica@enm.utcluj.ro, România \\ ${ }^{5}$ Technical University of Cluj-Napoca, Faculty of Electrical Engineering, office.cristif@gmail.com, România
}

\begin{abstract}
There are numerous and different ways to design an energy efficient street lighting system, but not always the best technical solution is the optimal economic solution as well. In this paper, we used two distinct software tools in order to obtain the optimal technical and economic solution for selecting street lighting technology. The first software used was DIALux, which is frequently applied in this field, assisting designers in choosing the most appropriate electrical installations and evaluating the technical performance of the chosen solutions. This tool determined the street lighting system variants for which there are predetermined configurations, so that the lighting parameters obtained are in accordance with the normative requirements of the lighting classes in which the roadways are included. Different ways of locating the luminaires and other parameters were changed to reach the best version that meets the qualitative requirements of the lighting technology. The second software used was the one developed by the authors, based on ELECTRE III method, which evaluated the technical solutions returned by DIALux against several criteria, taking into account the designer's preferences and constraints. The optimal technical and economic solution was obtained after ranking the variants by their performance at each criterion. The simulation experiment and the results returned suggested that the combination of the two software tools is comprehensive and effective and it can be used in this type of decisions at large scale.
\end{abstract}

\section{Introduction}

In recent years, public lighting systems are designed pursuing energy efficiency, not only for environmental reasons but also to decrease the energy consumption as well $[1,2]$. Energy efficient technologies should always be in accordance with the lighting standards, ensure an adequate photometrical performance, providing visual comfort and safety. These are the main conditions regarding the design of a street lighting installation, which are detailed in [3]. There are several computer programs that can be used to design a street lighting installation, but none of these software tools does not include energy efficiency as an analysis parameter [4].

Different methods were studied and several algorithms were developed in previous research papers in order to obtain energy efficient installations for street lighting systems. Using Sustainable Process Index methodology, a comparative study of different lighting technologies is developed in [5]. The available technologies, such as light emitting diode, compact fluorescent and high pressure sodium were analysed in order to obtain the more suitable green solutions. Another comparative study, between the performances of the light emitting diode and high pressure sodium technologies, is presented in [6], and in [7] are described several schemes using Solid-State Lighting (SSL) in order to increase the energy efficiency of street lighting technology. A wireless sensor network system is presented in [8], which can be used to control and monitor electrical variables. Energy efficiency is one of the requirements and it is demonstrated that the algorithm developed fulfils the requirements. Issues related to smart and advanced street lighting systems are presented in [2] and [9], where the control of the street technology is the main objective.

Besides all the technical design conditions, the economic aspect should also be taken into account when designing a street lighting installation. There are only a few studies presented in the related papers that considered both technical and economic perspectives when designing a street lighting system. Several of these papers are mentioned below. Thus, in [10] is proposed a decision making tool to solve a quadratic integer programming problem in order to reduce energy consumption and to ensure that the optimal allocation solution is selected, regarding energy retrofit interventions. In [11] and [12] the same multi-criteria decision method is used, ELECTRE III, in order to develop an Energy Action Plan and help local authorities to design more sustainable energy systems, and in the second paper to select the most

\footnotetext{
${ }^{*}$ Corresponding author: fagarasan_maria@yahoo.com
} 
appropriate street lighting installation with the best investment.

The rest of the paper is organized as follows: Section 2 describes the methodology of ELECTRE III method and the application of DIALux software; Section 3 presents the case study; in Section 4 the results are discussed and, finally, the conclusions are drawn.

\section{Methodology}

The software application DIALux was used to design the public lighting system. All the parameters (type of road, lighting class, the number of lanes, maintenance factor, reference value, maintenance cycle, road width and length, variants of the location of luminaires) were introduced and the program returned the most appropriate technical solutions, which represent the alternatives. These solutions were then analysed with the software developed based on ELECTRE III method in order to obtain the optimal economic solution.

The algorithm of the ELECTRE III method consists of the following phases [13-16]:

a) Establishing a set of data - in this phase are defined the following data: the alternatives and the criteria, which will compose the performance matrix, three types of thresholds: indifference $\left(\mathrm{q}_{\mathrm{i}}\right)$, preference $\left(\mathrm{p}_{\mathrm{i}}\right)$, and veto $\left(\mathrm{v}_{\mathrm{i}}\right)$, used to determine outranking relations and the weight indexes $\left(\mathrm{w}_{\mathrm{i}}\right)$, used to express the importance of each criterion $(i)$

b) Construction of the outranking relations - this phase includes three separate tests: concordance, discordance and credibility test. In each stage, there are calculate indexes for each pair of alternatives, based on separate equations.

The concordance index is calculated based on the statement "alternative $(A)$ outranks alternative $(B)$ ", using the following equation (1):

$c_{i}(A, B)=\left\{\begin{array}{l}1, \text { if } q_{i}\left(f_{i}(A)\right) \geq f_{i}(B)-f_{i}(A) \\ \frac{p_{i}\left(f_{i}(A)\right)+f_{i}(A)-f_{i}(B)}{p_{i}\left(f_{i}(A)\right)-q_{i}\left(f_{i}(A)\right)}, \text { if } p_{i}\left(f_{i}(A)\right)>f_{i}(B)-f_{i}(A)>q_{i}\left(f_{i}(A)\right) \\ 0, \text { if } p_{i}\left(f_{i}(A)\right) \leq f_{i}(B)-f_{i}(A)\end{array}\right.$

where:

$C(A, B)=\frac{1}{W} \cdot \sum_{i=1}^{n} w_{i} \cdot c_{i}(A, B)$

$f_{i}(A)$ - performance of alternative $A$ based on criterion $i$;

$f_{i}(B)$ - performance of alternative $B$ based on criterion $i$;

$q_{i}-$ indifference threshold for criterion $i$;

$p_{i}$ - preference threshold for criterion $i$.

Having the concordance indexes for all pairs, the global indicators, which form the concordance matrix, can be calculated using equation (2).

where:

$W$ - sum of all weights;

$w$ - weight of criterion $i$

$n$ - number of criteria;

$c_{i}(A, B)$ - concordance index with respect to criterion $i$.

The discordance indexes are calculated based on the statement "alternative $(A)$ outranks alternative $(B)$ ", using formula (3).

$D_{i}(A, B)=\left\{\begin{array}{l}0, \text { if } p_{i}\left(f_{i}(A)\right) \geq f_{i}(B)-f_{i}(A) \\ \frac{f_{i}(B)-f_{i}(A)-p_{i}\left(f_{i}(A)\right)}{v_{i}\left(f_{i}(A)\right)-p\left(f_{i}(A)\right)} \text {, if } v_{i}\left(f_{i}(A)\right)>f_{i}(B)-f_{i}(A)>p_{i}\left(f_{i}(A)\right) \\ 1, \text { if } v_{i}\left(f_{i}(A)\right) \leq f_{i}(B)-f_{i}(A)\end{array}\right.$

where:

$v_{i}$ - veto threshold for criterion $i$.

If the decision maker does not assign a veto threshold, the discordance indexes are null and the concordance matrix is the same as the credibility matrix.

In the final test the credibility matrix is developed, based on indexes calculated with equation (4).

$S(A, B)=\left\{\begin{array}{c}C(A, B), \text { if } C(A, B) \geq D_{i}(A, B) \forall i, \\ C(A, B) \cdot \prod_{i \in J(A, B)} \frac{\left(1-D_{i}(A, B)\right)}{(1-C(A, B))}\end{array}\right.$

where:

$J(A, B)$ - the criteria for which $D_{i}(A, B)>C(A, B)$.

c) Exploitation of the outranking relations - this phase includes two distillation procedures, called descending distillation and ascending distillation. These operations rank the alternatives depending on their performances in two pre-orders, which combined provide the final result.

\section{Case study}

The methodology presented above was applied to a public road, which has the following features:

a) Urban one-way road traffic with ME2 lighting class, four lanes, maintenance factor $=0.57$, reference value: external equipment, maintenance cycle: 3 years;

b) Road width: $l_{0}=14 \mathrm{~m}$, road length: $\mathrm{L}=1000 \mathrm{~m}$;

c) Variants of the location of luminaires: bilateral face to face, bilateral alternative.

To determine the technical solutions for the public road described above, there have been selected three types of luminaires: SELENIUM, IRIDIUM and MALAGA, combined with different lamps: high pressure mercury vapour discharge lamps (HPL-N), high pressure sodium lamps (SON-T) and light-emitting diode lamps (LED), with different wattage. In order to perform a technical optimization, there are three parameters that can be varied: the distance between pillars (considered between 30-47 m), pillar height (considered $8 \mathrm{~m}, 9 \mathrm{~m}, 10 \mathrm{~m}$ ) and the luminaire inclination. Thus, the data is input in DIALux and there are performed several simulations, which returned all the technical solutions that can be used to illuminate the public road. The first eighteen solutions, 
alternative A1 to alternative A18, where analysed and are presented in Table 1.

Table 1. The set of alternatives.

\begin{tabular}{|c|c|c|c|c|c|}
\hline Alternatives & Luminaire type & $\begin{array}{l}\text { Variants of the } \\
\text { location of luminaires }\end{array}$ & $\begin{array}{c}\text { Pillar } \\
\text { height }[\mathrm{m}]\end{array}$ & $\begin{array}{l}\text { Distance between } \\
\text { pillars }[\mathrm{m}]\end{array}$ & $\begin{array}{c}\text { Number of } \\
\text { pillars } \\
\text { [pes] }\end{array}$ \\
\hline A1 & $\begin{array}{l}\text { PHILIPS SGP340 FG 1xSON-TPP400W } \\
\text { TP P1 }\end{array}$ & bilateral alternative & 10 & 47 & 21 \\
\hline A2 & $\begin{array}{l}\text { PHILIPS SGS454 C FG 1xSON-TPP400W } \\
\text { SGR CP P2_220 }\end{array}$ & bilateral alternative & 10 & 44 & 22 \\
\hline $\mathbf{A 3}$ & $\begin{array}{l}\text { PHILIPS SGS453 C GB 1xSON-TPP250W } \\
\text { SGR CR P1_220 }\end{array}$ & bilateral alternative & 10 & 44 & 22 \\
\hline A4 & $\begin{array}{c}\text { PHILIPS SGS453 C GB 1xSON-TPP250W } \\
\text { SGR CR P1_220 }\end{array}$ & bilateral face to face & 10 & 41 & 24 \\
\hline A5 & $\begin{array}{c}\text { PHILIPS SGP340 FG 1xSON-TPP400W } \\
\text { TP P1 }\end{array}$ & bilateral face to face & 10 & 41 & 24 \\
\hline A6 & $\begin{array}{l}\text { PHILIPS SGP340 FG 1xSON-TPP250W } \\
\text { TP P1 }\end{array}$ & bilateral face to face & 10 & 37 & 27 \\
\hline A7 & $\begin{array}{l}\text { PHILIPS SGP340 FG 1xSON-TPP400W } \\
\text { TP P1 }\end{array}$ & bilateral alternative & 9 & 42 & 23 \\
\hline A8 & $\begin{array}{c}\text { PHILIPS SGS454 C FG 1xSON-TPP400W } \\
\text { SGR CP P2_220 }\end{array}$ & bilateral alternative & 9 & 39 & 25 \\
\hline A9 & $\begin{array}{c}\text { PHILIPS SGS453 C GB 1xSON-TPP250W } \\
\text { SGR CR P1_220 }\end{array}$ & bilateral alternative & 9 & 39 & 25 \\
\hline A10 & $\begin{array}{l}\text { PHILIPS SGS453 C GB 1xSON-TPP250W } \\
\text { SGR CR P1_220 }\end{array}$ & bilateral face to face & 9 & 36 & 27 \\
\hline A11 & $\begin{array}{c}\text { PHILIPS SGP340 FG 1xSON-TPP250W } \\
\text { TP P1 }\end{array}$ & bilateral face to face & 9 & 34 & 29 \\
\hline A12 & $\begin{array}{l}\text { PHILIPS SGP340 C FG 1xSON-TPP400W } \\
\text { TP P1 }\end{array}$ & bilateral face to face & 9 & 32 & 31 \\
\hline A13 & $\begin{array}{l}\text { PHILIPS SGP340 FG 1xSON-TPP400W } \\
\text { TP P1 }\end{array}$ & bilateral alternative & 8 & 36 & 27 \\
\hline A14 & $\begin{array}{l}\text { PHILIPS SGP340 C FG 1xSON-TPP250W } \\
\text { TP P1 }\end{array}$ & bilateral alternative & 8 & 31 & 32 \\
\hline A15 & $\begin{array}{l}\text { PHILIPS SGS453 C GB 1xSON-TPP150W } \\
\text { SGR CR P1_220 }\end{array}$ & bilateral alternative & 8 & 30 & 33 \\
\hline A16 & $\begin{array}{c}\text { PHILIPS SGP340 FG 1xSON-TPP250W } \\
\text { TP P1 }\end{array}$ & bilateral face to face & 8 & 31 & 32 \\
\hline A17 & $\begin{array}{c}\text { PHILIPS SGP340 C FG 1xSON-TPP250W } \\
\text { TP P1 }\end{array}$ & bilateral face to face & 8 & 30 & 33 \\
\hline A18 & $\begin{array}{l}\text { PHILIPS SGS454 C FG 1xSON-TPP400W } \\
\text { SGR CP P2_220 }\end{array}$ & bilateral face to face & 8 & 30 & 33 \\
\hline
\end{tabular}

For the study developed using the software based on ELECTRE III method, eight criteria had been considered. The first one, energy consumption $[\mathrm{kWh} / 1000 \mathrm{~h}]$ is determined for each variant, taking in consideration the number of luminaires needed to provide the minimum illuminance. Another criterion is luminous efficiency $[\mathrm{lm} / \mathrm{W}]$, which is inversely proportional with the first one and is calculated as division between the lamp luminous flux and the power consumed by the lamp.

The next criterion, IK protection [points], is specified by the manufacturer of the luminaires. The degrees of protection indicate the level of protection to external mechanical impact, and it differs for each type of luminaire.

The total price of the lighting system [RON], installation price [RON] and maintenance price [RON] are usually determined based on an auction, being a public project, where different companies offer a price to complete this work. The bidder who offers the lowest price wins the contract. Thus, these prices should be very advantageous. For this study, the prices were considered from a local company, which often participates at auctions for public lighting projects.

The lamp lifetime [h] and lamp warranty [months] differs depending on the lamp type, and the values for these two criteria are specified in the data sheet of the product.

The weights and the values for each threshold are given in Table 2, and the performance matrix, which consists of all the alternatives and criteria are presented in Table 3. 
Table 2. Thresholds and criteria weights.

\begin{tabular}{|c|c|c|c|c|c|c|c|c|}
\hline $\begin{array}{l}\text { Weights } \\
\text { Thresholds }\end{array}$ & $\begin{array}{c}\text { Energy } \\
\text { consumption } \\
{[\mathbf{k W h} / \mathbf{1 0 0 0 h}]}\end{array}$ & $\begin{array}{c}\text { Luminous } \\
\text { efficiency } \\
{[\mathbf{I m} / \mathbf{W}]}\end{array}$ & $\begin{array}{c}\text { IK } \\
{[\text { points] }}\end{array}$ & $\begin{array}{c}\text { Lighting } \\
\text { system price } \\
{[\mathbf{R O N}]}\end{array}$ & $\begin{array}{c}\text { Installation } \\
\text { price } \\
{[\mathbf{R O N}]}\end{array}$ & $\begin{array}{c}\text { Maintenance } \\
\text { price }[\mathbf{R O N}]\end{array}$ & $\begin{array}{c}\text { Lamp } \\
\text { lifetime } \\
{[\mathbf{h}]}\end{array}$ & $\begin{array}{c}\text { Lamp } \\
\text { warranty } \\
{[\mathbf{m o n} \text { (h)] }}\end{array}$ \\
\hline Indifference $(q)$ & 0.1 & 0.15 & 0.1 & 0.05 & 0.05 & 0.05 & 0.1 & 0.1 \\
\hline Preference $(p)$ & 0.2 & 0.25 & 0.2 & 0.15 & 0.15 & 0.15 & 0.2 & 0.25 \\
\hline Veto $(v)$ & 0 & 0 & 0 & 0 & 0 & 0 & 0 & 0 \\
\hline Weight $(w)$ & 0.2 & 0.15 & 0.05 & 0.25 & 0.1 & 0.15 & 0.05 & 0.05 \\
\hline
\end{tabular}

Table 3. Performance matrix

\begin{tabular}{|c|c|c|c|c|c|c|c|c|}
\hline Alternatives & $\begin{array}{c}\text { Energy } \\
\text { consumption } \\
{[\mathrm{kWh} / \mathbf{1 0 0 0 h}]}\end{array}$ & $\begin{array}{l}\text { Luminous } \\
\text { efficiency } \\
{[\operatorname{lm} / \mathbf{W}]}\end{array}$ & $\underset{\text { [points] }}{\text { IK }}$ & $\begin{array}{c}\text { Lighting } \\
\text { system price } \\
\text { [RON] }\end{array}$ & $\begin{array}{c}\text { Installation } \\
\text { price } \\
{[\mathrm{RON}]}\end{array}$ & $\begin{array}{l}\text { Maintenance } \\
\text { price [RON] }\end{array}$ & $\begin{array}{c}\text { Lamp } \\
\text { lifetime } \\
{[\text { [h] }}\end{array}$ & $\begin{array}{c}\text { Lamp } \\
\text { warranty } \\
\text { [months] }\end{array}$ \\
\hline A1 & 8400 & 101.7 & 10 & 56175 & 8820 & 2100 & 28000 & 60 \\
\hline A2 & 8800 & 114.41 & 8 & 62700 & 9240 & 2200 & 28000 & 48 \\
\hline A3 & 8800 & 112.88 & 8 & 56980 & 9240 & 2200 & 32000 & 48 \\
\hline A4 & 6000 & 112.88 & 8 & 62160 & 10080 & 2400 & 32000 & 48 \\
\hline A5 & 9600 & 101.7 & 10 & 64200 & 10080 & 2400 & 28000 & 60 \\
\hline A6 & 6750 & 82.88 & 10 & 65205 & 11340 & 2700 & 32000 & 60 \\
\hline A7 & 9200 & 101.7 & 10 & 55315 & 9660 & 2300 & 28000 & 60 \\
\hline A8 & 10000 & 114.41 & 8 & 64500 & 10500 & 2500 & 28000 & 48 \\
\hline A9 & 10000 & 112.88 & 8 & 58000 & 10500 & 2500 & 32000 & 48 \\
\hline A10 & 6750 & 112.88 & 8 & 62640 & 11340 & 2700 & 32000 & 48 \\
\hline A11 & 7250 & 82.88 & 10 & 62205 & 12180 & 2900 & 32000 & 60 \\
\hline A12 & 12400 & 101.7 & 10 & 74555 & 13020 & 3100 & 28000 & 60 \\
\hline A13 & 10800 & 101.7 & 10 & 59805 & 11340 & 2700 & 28000 & 60 \\
\hline A14 & 8000 & 82.88 & 10 & 62560 & 13440 & 3200 & 32000 & 60 \\
\hline A15 & 4950 & 93.33 & 8 & 66495 & 13860 & 3300 & 34000 & 48 \\
\hline A16 & 8000 & 82.88 & 10 & 62560 & 13440 & 3200 & 32000 & 60 \\
\hline A17 & 8250 & 82.88 & 10 & 64185 & 13860 & 3300 & 32000 & 60 \\
\hline A18 & 13200 & 114.41 & 8 & 78870 & 13860 & 3300 & 28000 & 48 \\
\hline
\end{tabular}

\section{Results}

In order to obtain the optimal economic solution for street lighting system it was used the software developed by the authors based on the ELECTRE III method algorithm.

After the criteria and alternatives were defined and the direction of the preference for each criterion was identified, the indifference, preference and veto threshold for each criterion were introduced.

The software returns complementary results: three types of matrices (the concordance matrix, the discordance matrix and the credibility matrix) that are determined using the methodology described at Section 2. Figure 1 shows the credibility matrix calculated by the application, which is identical to the concordance matrix because the veto threshold was not defined and the discordance indexes are null. 


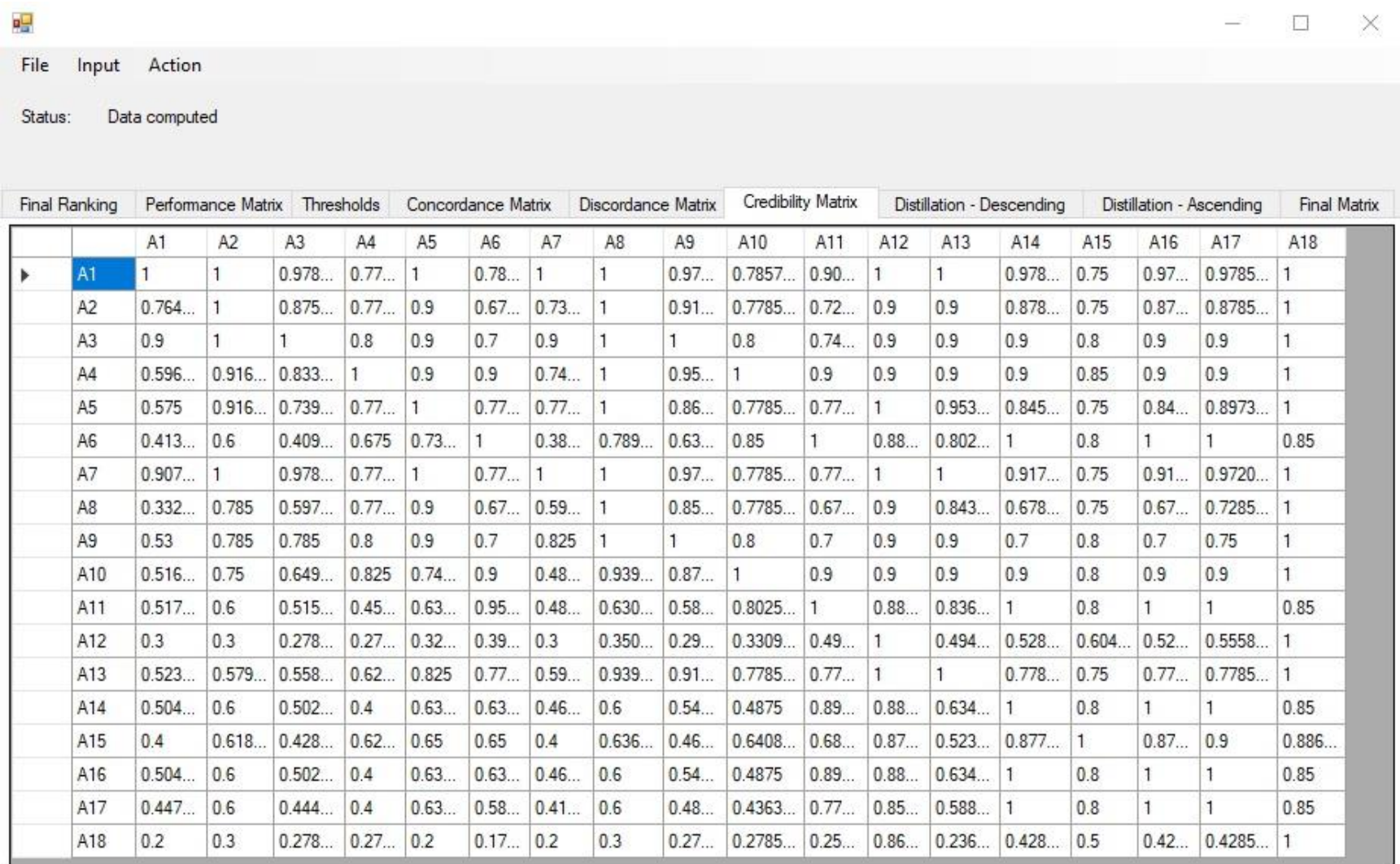

Fig. 1. Credibility matrix

The next step is to perform the two distillation procedures, based on the credibility matrix. The software ranks the alternatives in two pre-classifications, descending and ascending, which are presented in figures 2 and 3. The descending distillation is computed by selecting first the best ranked alternatives and ending with the worst. The ascending distillation is the reverse operation, successive removal of the worst alternative and ending with the best.

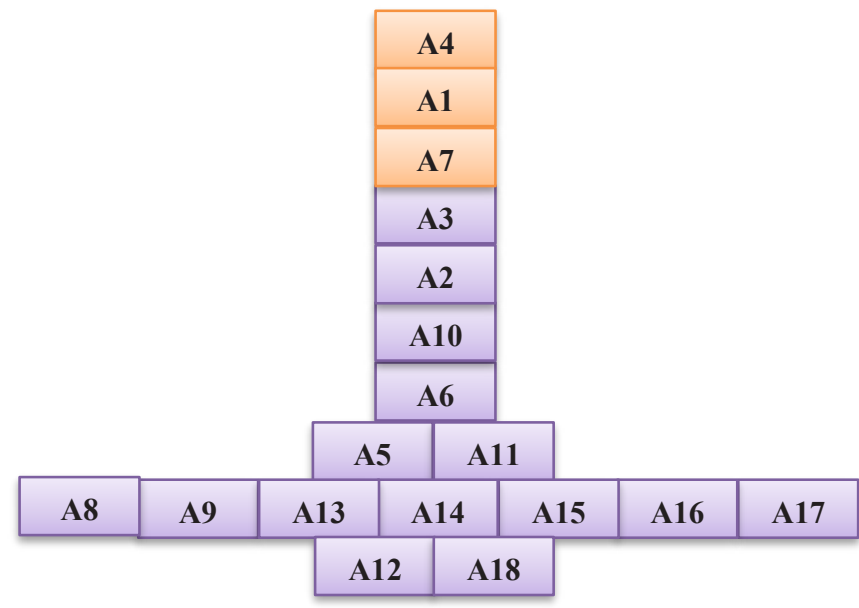

Fig. 2. Descending distillation.

After the descending distillation, A4 is ranked as the best alternative, followed by A1 and A7. At the other extreme, A12 and A18 are at the same place, being ranked as the worst alternatives.

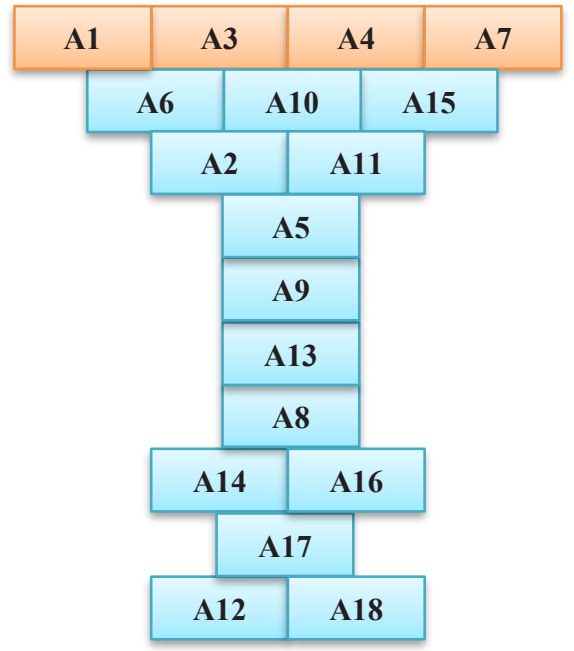

Fig. 3. Ascending distillation.

The results after the ascending distillation show that four alternatives are ranked as the best, the software not being able to distinguish between their performances. These alternatives are A1, A3, A4 and A7. Regarding the worst alternatives, the results are the same as the ones from the descending distillation: A12 and A18.

\footnotetext{
${ }^{*}$ Corresponding author: fagarasan_maria@yahoo.com
} 
The two pre-orders obtained after the distillation procedures, are combined and used to determine the final ranking, as presented in figure 4.

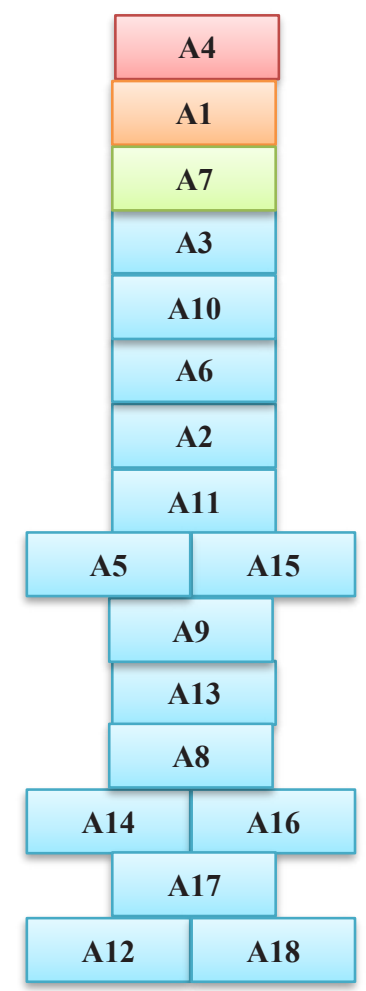

Fig. 4. Final ranking

The final ranking reveals the optimal technical and economic solution for the street lighting system designed in this study, which is alternative A4. Thus, using PHILIPS SGS453 C GB 1xSON-TPP250W SGR CR P1_220 luminaires on pillars which have $10 \mathrm{~m}$ height and the distance between them of $41 \mathrm{~m}$ is the best solution from all alternatives taken into consideration in this analysis.

The next best ranked alternatives are A1 and A7, meaning using the PHILIPS SGP340 FG 1xSONTPP400W TP P1 and PHILIPS SGP340 FG 1xSONTPP400W TP P1 luminaires on pillars which have $10 \mathrm{~m}$ and $9 \mathrm{~m}$ height, and the distance between them being of $47 \mathrm{~m}$, respectively $42 \mathrm{~m}$.

\section{Conclusions}

In this paper, the combination of two separate software applications was proposed in order to design a high energy efficient street lighting system. DIALux and the software developed by the authors based on ELECTRE III method were used to select the optimal technical and economic solution from all the alternatives included in the analysis. Eighteen luminaires combined with different types of lamps have been identified as technical solutions, which were obtained by varying different parameters, such as: the location of the luminaires, the distance between the pillars and the pillar height. The technical solutions returned by DIALux were then assessed from economic point of view, by using eight criteria: energy consumption, luminous efficiency, the degree of protection to external mechanical impact, lighting system, installation and maintenance price and lamp lifetime and warranty. After running the software, the final ranking revealed the best ranked alternatives.

The results obtained using the combination between DIALux, to select the technical solutions, and the software based on ELECTRE III method, to point the best economic solution, underline that this concept is comprehensive and effective and it can be used in the lighting technology design field at large scale.

\section{References}

1. R. Carli, M. Dotoli, R. Pellegrino, Comput. Oper. Res. 1 (2017)

2. I. Wojnicki, S. Ernst, L. Kotulski, A. Sedziwy, Expert Syst Appl. 41, 999 (2014)

3. M. Kostic, L. Djokic, Energy 34, 1565 (2009)

4. O. Rabaza, D. Gomez-Lorente, F. Perez-Ocon, A. Pena-Garcia, Energy 107, 831 (2016)

5. K. Shahzad, L. Cucek, M. Sagir, N. Ali, M.I. Rashid, R. Nazir, A.S. Nizami, H.A. Al-Turaif, I.M. Ibrahim Ismail, J. Cleaner Prod. 175, 683 (2018)

6. S. Yoomak, C. Jettanasen, A. Ngaopitakkul, S. Bunjongjit, M. Leelajindakrairerk, Energy Build. 159, 542 (2018)

7. M. Fontoynont, C.R. Physique

8. R. Pantoni, D. Brandao, Comput. Electr. Eng. 37, 1147 (2011)

9. D. Jin, C. Hannon, Z. Li, P. Cortes, S. Ramaraju, P. Burgess, N. Buch, M. Shahidehpour, Electr. J. 29, 28 (2016)

10. R. Carli, M. Dotoli, E. Cianci, IFAC PapersOnLine 50-1, 14460 (2017)

11. D. Neves, P. Baptista, M. Simoes, C.A. Silva, J.R. Figueira, J. Cleaner Prod. 176, 251 (2018)

12. J.A. Lobao, T. Devezas, J.P.S. Catalao, Energy Rep. 1, $110(2015)$

13. G. Fancello, M. Carta, P. Fadda, Transp. Res. Procedia 3, 175 (2014)

14. C. Cristea, M.Cristea, COSME'16 4, 9 (2016)

15. J. Zak, M. Kruszynski, Transp. Res. Procedia 10, 820 (2015)

16. J. Zak, Transp. Res. Procedia 27, 43 (2017) 